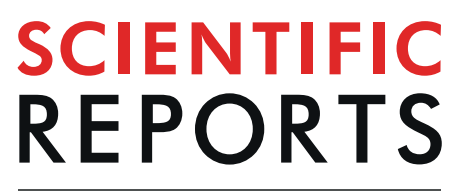

natureresearch

\title{
Comparison of Escherichia coli surface attachment methods for single-cell microscopy
}

\author{
Yao-Kuan Wang ${ }^{1,4}$, Ekaterina Krasnopeeva ${ }^{2,4}$, Ssu-Yuan Lin ${ }^{1}$, Fan Bai ${ }^{3}$, Teuta Pilizota ${ }^{2 *}$ \& \\ Chien-Jung Lo ${ }^{1 *}$
}

For in vivo, single-cell imaging bacterial cells are commonly immobilised via physical confinement or surface attachment. Different surface attachment methods have been used both for atomic force and optical microscopy (including super resolution), and some have been reported to affect bacterial physiology. However, a systematic comparison of the effects these attachment methods have on the bacterial physiology is lacking. Here we present such a comparison for bacterium Escherichia coli, and assess the growth rate, size and intracellular $\mathrm{pH}$ of cells growing attached to different, commonly used, surfaces. We demonstrate that $E$. coli grow at the same rate, length and internal $\mathrm{pH}$ on all the tested surfaces when in the same growth medium. The result suggests that tested attachment methods can be used interchangeably when studying $E$. coli physiology.

Microscopy has been a powerful tool for studying biological processes on the cellular level, ever since the first discovery of microorganisms by Antonie van Leeuwenhoek back in 17th century ${ }^{1}$. Recently employed single-cell imaging allowed scientists to study population diversity ${ }^{2}$, physiology $y^{3}$, sub-cellular features ${ }^{4}$, and protein dynamics ${ }^{5}$ in real-time. Single cell imaging of bacteria is particularly dependent on immobilisation, as majority of bacteria are small in size and capable of swimming. Immobilisation methods vary depending on the application, but typically fall into one of the two categories: use of physical confinement or attachment to the surface via specific molecules. The former group includes microfluidic platforms capable of mechanical trapping ${ }^{6,7}$, where some popular examples include the "mother machine", ${ }^{\text {" }}$ CellASIC" or MACS $^{10}$ devices, and porous membranes such as agarose gel pads ${ }^{2,11-13}$. Physical confinement methods, while higher in throughput, can have drawbacks. For example, agarose gel pads do not allow fast medium exchange, and when mechanically confining bacteria the choice of enclosure dimensions should be done carefully in order to avoid influencing the growth and morphology with mechanical forces ${ }^{14}$. Furthermore, mechanically confined bacteria cannot be used for studies of bacterial motility or energetics via detection of bacteria flagellar motor rotation ${ }^{15-17}$. Chemical attachment methods rely on the interaction of various adhesive molecules, deposited on the cover glass surface, with the cell itself. Adhesion can be a result of electrostatic (polyethylenimine (PEI) ${ }^{18,19}$, poly-L-lysine (PLL) ${ }^{15,17,19}$ ) or covalent interactions (3-aminopropyltriethoxysilane (APTES) ${ }^{19}$ ), or a combination, such as with polyphenolic proteins (Cell-Tak ${ }^{19}$.

Time scales on which researchers perform single-cell experiments vary. For example, scanning methods, like atomic force microscopy (AFM) or confocal laser scanning microscopy (CLSM) ${ }^{19,20}$, require enough time to probe each point of the sample, and stochastic approaches of super resolution microscopy (e.g. PALM and STORM) use low activation rate of fluorophores to achieve a single fluorophore localisation ${ }^{20,21}$. Thus, required acquisition time scales vary from milliseconds to minutes ${ }^{21,22}$, while experiments aimed at the observation of cell growth or slow cellular responses can run from minutes to hours ${ }^{8,11,16,23,24}$.

Regardless of the time scale, physiology of the studied bacteria should not be affected by the adhesives used for surface attachment. For example, single particle tracking is often performed on surface immobilised cells $s^{5,25,26}$, and cellular physiology can influence particle diffusion in the cytoplasm, e.g. metabolic "stirring" of the cytoplasm enhances diffusion in size dependant manner ${ }^{27,28}$, and intracellular $\mathrm{pH}$ of yeast has been shown to affect cytoplasm fluidity ${ }^{29}$. Furthermore, concerns have been raised that charged molecules, like PLL that is commonly

${ }^{1}$ Department of Physics and Graduate Institute of Biophysics, National Central University, Jhongli, Taiwan, 32001, Republic of China. ${ }^{2}$ Centre for Synthetic and Systems Biology, Institute of Cell Biology, School of Biological Sciences, University of Edinburgh, Alexander Crum Brown Road, EH9 3FF, Edinburgh, UK. ${ }^{3}$ Biodynamic Optical Imaging Center (BIOPIC), School of Life Sciences, Peking University, Beijing, 100871, China. ${ }^{4}$ These authors contributed equally: YaoKuan Wang and Ekaterina Krasnopeeva. *email: teuta.pilizota@ed.ac.uk; cjlo@phy.ncu.edu.tw 
used for a surface attachment ${ }^{17,24,25,30,31}$, can perturb membrane potential causing partial or complete membrane depolarisation ${ }^{32,33}$. Additionally, PLL in high concentrations exhibits antimicrobial properties ${ }^{34}$. Despite of these concerns, PLL has been widely utilized in super-resolution and single molecules tracking applications as it is cheap and easy to use ${ }^{35,36}$. Previous studies of bacterial attachment focused mostly on AFM applications, thus visually assessing the strength of the attachment and reporting cells viability immediately upon attachment ${ }^{19,37,38}$. However, characterisation of physiological parameters on different surfaces, and on the time scales relevant for live cell imaging, while important, is lacking.

In this report we compare a range of immobilisation techniques, including PLL, PEI, Cell-Tak and agarose gel pad, using Escherichia coli as a model organism. We measure several physiological traits during growth on the specific surface, including growth rate, size and intracellular $\mathrm{pH}$, and find that tested immobilisation methods do not differ; growth rate and cell size are surface-attachment independent.

\section{Results}

Immobilisation assays. We test four substrates commonly used for bacteria immobilisation: poly-L-lysine $(\mathrm{PLL})^{15,33}$, polyethylenimine (PEI) ${ }^{18,39}$, Cell-Tak ${ }^{19}, 3$-aminopropyltriethoxysilane (APTES $)^{19}$ and agarose gel ${ }^{22}$.

PLL and PEI are cationic polymers, which can electrostatically interact with negative charges on the outer surface of the cell ${ }^{40}$. Several PLL coating protocols have been reported, which we here refer to as "in-chamber" 15 , "rinsed" ${ }^{33}$, and "air-dried" 33 methods. "In-chamber" PLL coating is the most standard for bacterial flagellar motor experiments commonly known as bead assay ${ }^{15,41-43}$. In this protocol PLL solution is flushed into an uncoated glass flow-chamber for no longer than $15 \mathrm{~s}$ followed by thorough washing with the excessive volume of growth medium ( 25 times the flow-chamber volume). In the "rinsed" method lower PLL concentration and longer incubation time ( $\mathrm{min}$ ) are used to cover the entire surface of the coverslip by immersing it in the PLL solution ${ }^{33}$ and subsequent washing. "Air-dried" method is similar to the "rinsed", with an addition of complete drying the PLL solution on the coated surface for over an hour before washing. For our detailed coating protocols see Materials and Methods.

Cell-Tak is a commercially available adhesive extracted from marine mussel, Mytilus edulis. It's a component of byssus, a bundle of filaments mussels secrete to anchor themselves to solid surfaces ${ }^{44,45}$. Characterising and mimicking the adhesive chemistry of mussel byssus is an active area of research ${ }^{46}$. What we know thus far, is that it involves bidentate and covalent interactions, protein coacervation, intrinsic protein-protein binding as well as metal chelation ${ }^{46}$. We use the manufacturer coating protocol as described in Materials and Methods.

APTES is a common choice for salinisation of microfluidic channels ${ }^{47}$, and has also been employed as an attachment agent for the AFM imaging ${ }^{19}$. We coat coverslips by incubating them in a $2 \%$ solution of APTES for $2 \mathrm{~h}$ followed by extensive washing with water and acetone as described in Materials and Methods.

As a control we grow bacteria on the agarose gel pad with no chemical adhesives (see Materials and Methods for details).

Growth rate and morphology of bacteria do not depend on the surface attachment method. To estimate the effect of different immobilisation assays on bacterial physiology we examine the growth rate, size and division accuracy of individual cells growing on each specific surface. The growth regulation of bacteria has been attracting researchers attention since $1950 \mathrm{~s}$. As a result, steady state population growth rates at different carbon sources and temperatures ${ }^{48,49}$, the nature of single cell growth and its connection with the population growth $^{50-53}$, the relationship between cell size and growth rate $e^{48,54}$, as well as the accuracy and robustness of cell division, have all been established ${ }^{8,55,56}$. The population growth rate $(\lambda)$ was found to depend on the nutritional composition of the media, and was slower at lower temperatures ${ }^{48,57}$. Here $\lambda$ refers to the cell population growing exponentially, also called balanced growth or steady state growth, so that $N(t)=N_{0} \cdot e^{\lambda t}$, where $N(t)$ is the number of cells at a given time point $t$. As the number of cells in the population doubles with a specific doubling time $t_{D}, N(t)$ can be expressed as $N(t)=N_{0} \cdot 2^{t / t_{D}}$, and $\lambda=\ln (2) / t_{D}$. Individual cells within the population were also found to grow exponentially, specifically in mass and length ${ }^{50,51}$. Thus, $L(t)=L_{b} \cdot e^{b t}$, where $L_{b}$ is the cell length at birth and $b$ the growth rate of an individual cell, which is equal to $b=\ln \left(L_{d} / L_{b}\right) / t_{D}{ }^{52,53}$. $L_{d}$ is a cell length at division and in $E$. coli it is equal to two lengths of the cell at birth ${ }^{8,55,56}$. Therefore, to a good approximation $\lambda=b$ (if noise is taken into the account the population growth rate is slightly lower when compared to $b^{52,53}$ ). In summary, from previous work we expect that if the specific surface attachment method does not alter cells' physiology in comparison to planktonic growth, $b$ will be equal to $\lambda$ (for a given medium and temperature), the cell size should be a function of growth rate and the cells should divide in half.

To obtain $b$ and cell size we monitor bacteria between the first and second divisions $\left(G_{1}\right.$ and $G_{2}$, see also Materials and Methods and Fig. 1, top) using optical microscopy. Phase-contrast images of the bacteria are taken every $5 \mathrm{~min}$ and cells' length and width $(W)$ are extracted as described in Materials and Methods and Fig. 1A. Prior to imaging cells are grown in a flask at $37^{\circ} \mathrm{C}$ and later kept at $23^{\circ} \mathrm{C}$ during flow chamber preparation for $\sim 40 \mathrm{~min}$ (see also Materials and Methods). Bacterial growth assay is then performed at $23^{\circ} \mathrm{C}$ in a flow chamber. SI Fig. 1 shows growth rates and bacterial length versus time from the beginning of the imaging $\left(G_{0}\right.$ to $G_{2}$ as defined in Fig. 1 , top), indicating that by the time $G_{1}$ is reached, cells' growth rate is approximately constant. Thus, unless explicitly stated, from here on we combine $b, L$ and $W$ from $G_{1}$ and $G_{2}$. During imaging fresh oxygenated medium is continuously supplied to the cells.

Figure 1B shows that single cell growth rates of the cells grown on different surfaces are independent of the surface attachment and in agreement with population growth rates measured by us (SI Fig. 5 and Table 1 and SI 2), and reported previously ${ }^{48,49}$ (for comparison between $G_{1}$ and $G_{2}$ see SI Fig. 3). As expected, the growth rate is medium dependant and increases when we move from the MM9 medium (see Materials and Methods) to the richer LB medium (SI Fig. 4A). 

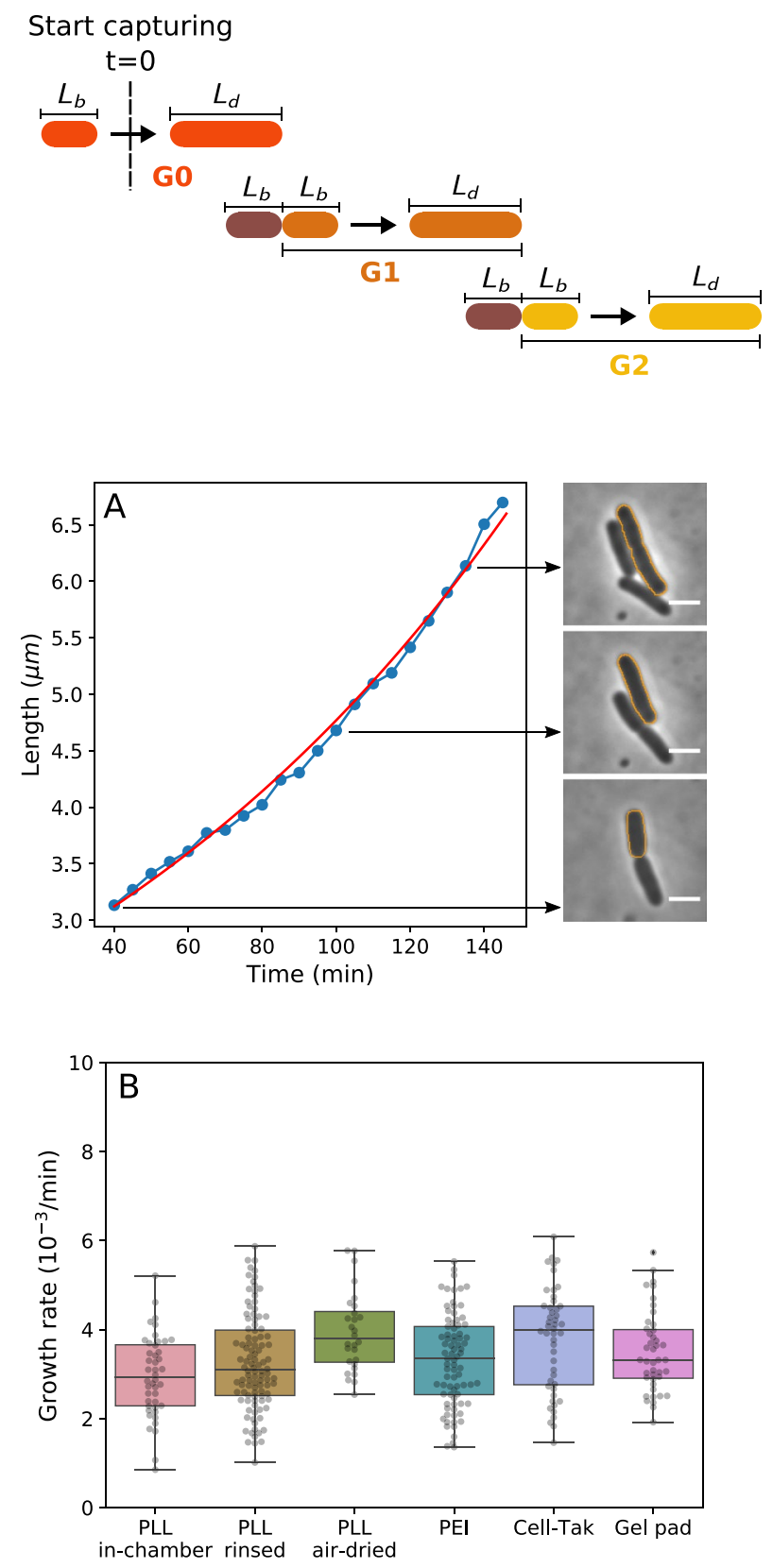

Figure 1. Bacterial growth rate stays constant when cells are attached to the surface with different attachment methods.Top, a cartoon depicting our imaging protocol. $G_{0}$ are the cells observed upon commencing the imaging to the first visible division. Subsequent two generations $\left(G_{1}\right.$ and $\left.G_{2}\right)$ are used to obtain our results (unless otherwise stated). (A) The single cell length is measured using phase contrast imaging over a complete first generation (G1) cell cycle. Because individual E.coli cells have been shown to grow exponentially ${ }^{50,51}$, we fit their length to a single exponential function $\left(L(t)=L_{b} \times e^{b t}\right.$, see also Materials and Methods) from which we obtain the single cell growth rate. The red line shows the fit and fitting parameters $L_{b}$ and $b$ are $3.12 \mu \mathrm{m}$ and $0.007 \mathrm{~min}^{-1}$, respectively (see also Table 1 ). The diagram above (A) shows the definition of different generations. We call the generation zero (G0) cells that were deposited onto the surface after their growth on the flask. We start our observation in the middle of the G0 growth cycle. G0 is followed by the generation one (G1) that lasts from the first observed division to the second, and so on. Panel on the right shows the phase contrast images of the tracked cell (marked with the orange outline) at the indicated time points. Scale bar is 2. (B) Comparison of average growth rates on different surfaces shows no significant difference between all tested immobilisation methods in MM9 medium. The growth rates were measured at $23^{\circ} \mathrm{C}$. Number of cells analysed for each attachment method is: $\mathrm{N}=44,104,28,81,48$, and 43 for "PLL in-chamber", "PLL rinsed", "PLL air-dried”, PEI, Cell-Tak and gel pad respectively.

In Fig. 2A,B and Table 1 we analyse the length of individual cells at the beginning (length at birth, $L_{d}$ ) and at the end of the growth cycle (length at division, $L_{d}$ ), as well as cell width $(W)$ ). Similarly to the growth rates, $L_{b}, L_{d}$, and $W$ are not dependant on the immobilisation method, but do change with the growth media, SI Fig. 4B,C. 


\begin{tabular}{|l|l|l|l|l|l|l|l|l|l|}
\hline Medium & $\boldsymbol{b}\left(\mathbf{m i n}^{-1}\right)$ & $\boldsymbol{\lambda}\left(\mathbf{m i n}^{-1}\right)$ & $\boldsymbol{L}_{\boldsymbol{b}}(\boldsymbol{\mu m})$ & $\boldsymbol{L}_{\boldsymbol{d}}(\boldsymbol{\mu m})$ & $\boldsymbol{W}(\boldsymbol{\mu m})$ & $\boldsymbol{L}_{\boldsymbol{b}} / \boldsymbol{L}_{\boldsymbol{d}}$ & $L_{\text {daughter }} / \boldsymbol{L}_{\text {mother }}$ & $\boldsymbol{p} \boldsymbol{H}_{\text {initial }}$ & $\boldsymbol{p} \boldsymbol{H}_{\text {final }}$ \\
\hline MM9 & $0.0033 \pm 0.0010$ & 0.0032 & $2.61 \pm 0.31$ & $4.35 \pm 0.49$ & $0.94 \pm 0.04$ & $0.60 \pm 0.07$ & $0.50 \pm 0.03$ & $8.39 \pm 0.33$ & $7.82 \pm 0.24$ \\
\hline LB & $0.0083 \pm 0.0011$ & 0.0080 & $3.31 \pm 0.54$ & $5.72 \pm 0.95$ & $1.03 \pm 0.07$ & $0.58 \pm 0.07$ & $0.50 \pm 0.02$ & $8.29 \pm 0.16$ & $8.43 \pm 0.16$ \\
\hline
\end{tabular}

Table 1. Summary of the experimentally measured variables. Experiments were performed in LB only in the gel pad. Results obtained for $G_{1}$ and $G_{2}$ phase on each different surfaces (including gel pad) are averaged.
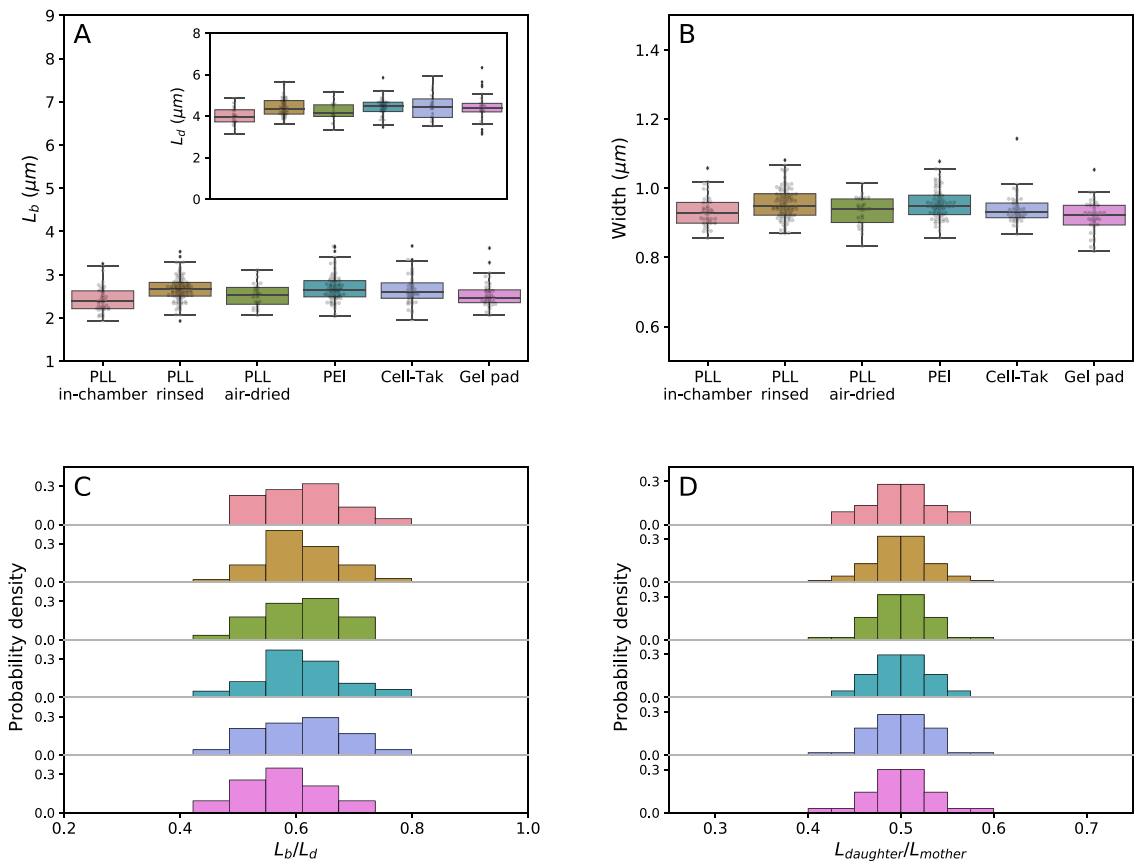

Figure 2. Morphology of bacteria is not influenced by the attachment method, but does change when cells grow on a surface. (A) Cell length at birth $\left(L_{b}\right)$ of cells immobilised on different surfaces. The inset shows the length at division. (B) Width distribution of cells attached to the surface with various coatings remains constant. (C) Probability density of length ratio $\left(L_{b} / L_{d}\right)$ and (D) $\left(L_{\text {daughter }} / L_{\text {mother }}\right)$ remains unchanged on all tested surfaces. Colour coding is as given in $(\mathbf{A}, \mathbf{B})$.

However, cells growing on the surface, while growing at the same rate as planktonic cells, divide earlier and become shorter, and equally so on all the surfaces, Fig. 2C. Thus, planktonic $t_{D}=\ln (2) / \lambda$ and $t_{D}=\ln \left(L_{d} / L_{b}\right) / b$ of cells growing on the surface are not the same despite the same growth rates (Figure SI Fig. 3 shows $\left.t_{D}=\ln \left(L_{d} / L_{b}\right) / b\right)$. When growing on different surfaces cells still divide in half, as shown in Fig. 2D and SI Fig. 2C, where we plot the length of the mother and daughter cells $\left(L_{\text {daughter }} / L_{\text {mother }}\right)$. We note that this ratio is between two generations, whereas $L_{b} / L_{d}$ is within one generation (as defined in Fig. 1). We summarise our and previous population growth rates in SI Table 2 and all other experimentally measured variables in Table 1.

Cells can grow and divide while attached to the APTES coated surface. However, we were unable to calculate the growth rate, shape or the internal $\mathrm{pH}$ due to poor quality of attachment (most of the cells on APTES surface detached withing the first generation). Time lapse video demonstrating cell growth and attachment on APTES coated surface is shown in SI Video 1, in comparison to growth on other surfaces shown in SI Videos 2 to 7.

Intracellular pH during growth on the surface does not depend on the method of attachment. Neutrophilic bacteria maintain their cytoplasmic $\mathrm{pH}$ withing a narrow range (termed $\mathrm{pH}$ homeostasis). For example, E. coli can survive in a range of external pHs, starting as low as $\mathrm{pH} \sim 2$ in the human stomach and up to $\mathrm{pH} \sim 9$ at the pancreatic duct, while maintaining internal $\mathrm{pH}$ in a relatively narrow range of $7-8^{58-63}$. Cytoplasmic $\mathrm{pH}$ plays an important role in cellular energetics as the difference between cytoplasmic and extracellular $\mathrm{pH}$ contributes to the electrochemical gradient of protons (so called proton motive force ${ }^{64}$ ), as well as influences protein stability and an enzymatic activity in the cell ${ }^{65}$. However, cytoplasmic $\mathrm{pH}$ can change when cells are subjected to an external stress, such as acid or osmotic shocks ${ }^{62,66,67}$. Furthermore, for some species acidification of the cytoplasm has been shown to be related to pathogenicity ${ }^{68,69}$, and in yeast changes in the internal $\mathrm{pH}$ affect particle diffusion in the cytoplasm ${ }^{29}$. Here we investigate if surface attachment methods influence the internal $\mathrm{pH}$ of bacteria during time lapse imaging.

To monitor the effect of the adhesives on the internal $\mathrm{pH}$ of $E$. coli during growth, we use a genetically encoded indicator pHluorin ${ }^{17,70,71}$. pHluorin is a variant of the green fluorescent protein with $\mathrm{pH}$ sensitive spectrum that 

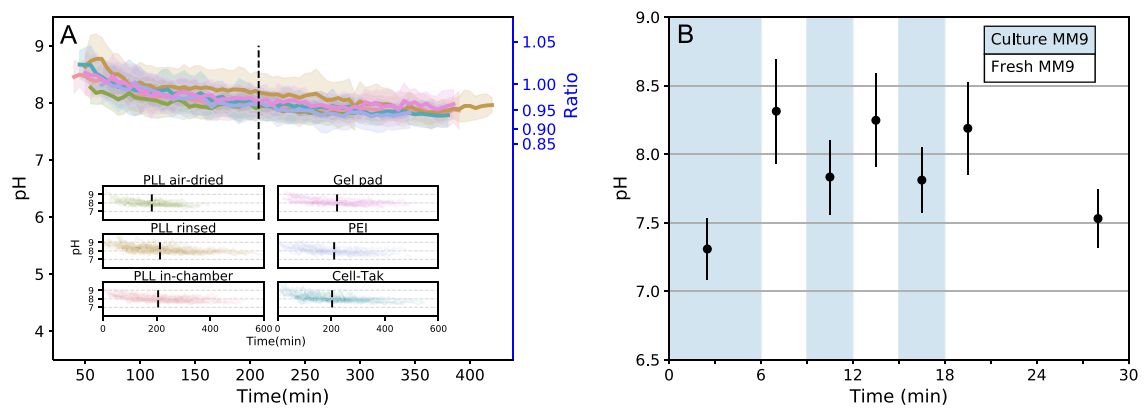

Figure 3. Intracellular $\mathrm{pH}$ dynamics of bacterial cells immobilised on a given surface. (A) Single cell intracellular $\mathrm{pH}$ is measured with cytoplasmic pHluorin during cell growth on different surfaces. Solid line and shaded area show the mean and standard deviation. Dashed line separates the mean first and second generations of bacteria. All tested immobilisation methods exhibit similar tendencies: $\mathrm{pH}$ values start from $\mathrm{pH}$ $8.38 \pm 0.29$ and decrease to about $\mathrm{pH} 7.78 \pm 0.16$ within $\sim 7 \mathrm{~h}$ of observation. The inset shows all single-cell traces plotted for each condition. (B) Cells in a flow chamber are sequentially treated with the medium taken from a growing culture (blue regions) and fresh medium (white regions). Media exchange occurs in a short pulse manner at the beginning of each period, while no flow is applied during imaging. Data points show the mean of $\mathrm{N}>500$ measured bacteria with standard deviation as error bar.

responds in a ratiometric manner, SI Fig. 6. Prior to the growth experiments, pHluorin has been calibrated in vivo and in vitro, see Supplementary Methods ${ }^{17}$. For in vivo calibration we used various $\Delta p H=p H_{\text {external }}-p H_{\text {int ernal }}$ collapsing agents and noticed that the calibration curves deviate slightly depending on the uncoupler, which compromises the accuracy of the potential $\mathrm{pH}$ measurements. Though it is not clear what causes the difference in the calibration curves ${ }^{17}$, we show that the combination of potassium benzoate and methylamine hydrochloride (PBMH) allows us to reproduce the in vitro calibration most accurately (SI Fig. 7), and we subsequently use $\mathrm{PBMH}$ for in vivo calibration.

Having calibrated pHluorin, we measure the intracellular $\mathrm{pH}$ of the immobilised bacteria during growth and division, and as before tracking the two generations $\left(G_{1}\right.$ and $\left.G_{2}\right)$. Figure 3 shows that cytoplasmic $\mathrm{pH}$ of cells grown in MM9 decreases on all tested surfaces, dropping mainly in the first generation (SI Fig. 8 shows cell to cell variation). In contrast, cytoplasmic $\mathrm{pH}$ of the cells growing in LB slightly increases over both generations as depicted in the SI Fig. 9.

The intracellular $\mathrm{pH}$ values we measured (Table 1) are higher than those commonly found in the literature $\left(7.2-7.8^{61,62}\right)$. We assume these discrepancies originate from the fact that we constantly exchange the medium during the cell growth, removing from the environment metabolic waste products and any quorum sensing or signal molecules, which have previously been shown to influence cytoplasmic $\mathrm{pH}^{63,72,73}$. Indeed, when cells are kept in the original growth medium their cytoplasmic $\mathrm{pH}$ varies between 7.3 and 7.7, Fig. 3B. It, however, increases rapidly to $8.2-8.3$ when fresh medium is supplied and can be reduced back to $\sim 7.8$ upon the return to the original growth medium, Fig. 3B. Further incubation in a fresh medium with no exchange (flow has been stopped) leads to the $\mathrm{pH}$ decrease to $\sim 7.5$ after $\sim 10 \mathrm{~min}$.

Attachment quality on different surfaces varies. For single cell imaging it is important that analysed cells remain "flat"18,24 (long axis parallel to the imaging plane) for the duration of observation, which could last several generations. We quantified the flatness by comparing the phase-contrast image intensity from two sides of the cells and defining a flatness score, Fig. 4A (see Materials and Methods for details). All of the surfaces on which we obtained growth rates, "PLL in-chamber", "PLL rinsed", "PLL air-dried", PEI and Cell-Tak show similar attachment quality during cell growth and division, Fig. 4B. Interestingly, at the beginning of the observation even on APTES surface we find "flat" cells and correspondingly report a low flatness score in Fig. 4B. Thus, grown in our media E. coli attaches to the APTES coated surface along the whole cell body, but it does so weakly (see SI Video 1). Images obtained on these surfaces with phase-contrast microscopy are indistinguishable, Fig. 4C. In comparisons, cells on the gel pad surface are'flat' as well, but we observe agarose impurities that influence image quality, Fig. 4C.

\section{Discussion}

Good surface attachment is an important requirement for bacterial single-cell studies using optical microscopy. However, we are unaware of a systematic study that characterises the effects on cells' physiology caused by different adhesives. Changes in the cellular physiology caused by different surface attachment methods can influence not only studies of cellular physiology themselves, but also studies focusing on specific cellular molecular mechanisms. For example, metabolic rate or internal $\mathrm{pH}$ could lead to the alteration of cytoplasm properties, e.g. its fluidity ${ }^{27,29}$, and many intracellular processes, including DNA replication and cell division, are highly dependent on the growth $\operatorname{rate}^{74,75}$. It is, therefore, important to consider and characterise potential effects of the immobilisation method on physiology of the studied bacteria.

Here, we test a range of the immobilisation techniques and show that $E$. coli's growth rate and shape are immobilisation method independent. Cell length and the growth rate are dependent on the growth medium, 

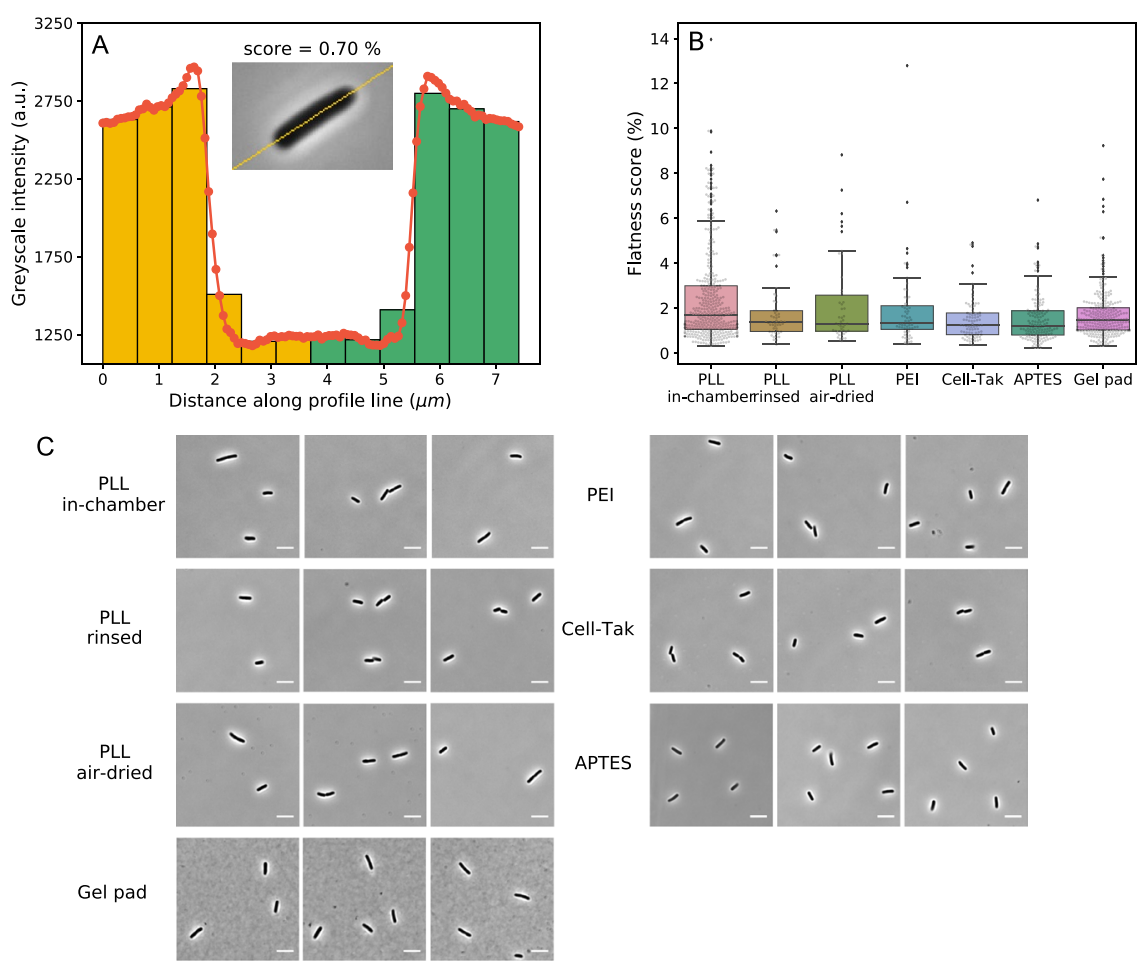

Figure 4. (A) The flatness score is calculated from the difference in the intensity between the two halves of the cell. Histogram of the intensity taken along the mid-line of the cell (inset) is shown. Two sides of the cells are indicated with yellow and green colour. Intensity of bins on the left and right that are equidistant from the middle are subtracted, and summed to obtained the flatness score. (B) Box plot (see Materials and Methods for details) of flatness scores on different surfaces obtained from 401, 51, 46, 61, 84, 143, and 269 cells for each of the surfaces (collected over $\sim 130^{2}$ flow chamber surface area), respectively. Here flatness score of $0 \%$ corresponds to a perfectly flat cell. (C) Examples of phase contrast images of E. coli cells attached to the surface with different immobilisation methods (scale bar is 5). All images shows good "flatness" (see Materials and Methods for details) and contrast for cell morphology tracking.

as expected, but independent of the surface attachment chemistry. We do, however, observe shortening of cells grow on the surface (Fig. 2C and SI Figs. 1 and 2), indicating an interesting physiological adaptation to growth on surface.

Though the concerns regarding use of PLL for surface attachment have been previously expressed in the literature ${ }^{32,76}$, we note that the experiments that demonstrate inhibition of cell division by PLL, do so for the case of free PLL molecules in the medium ${ }^{33}$. We show that all three of the tested PLL-coating protocols leave no residual PLL in the medium and do not influence bacterial growth rate and accuracy of the division. It is possible that we see no adverse effects during growth on the PLL surface due to lower overal concentrations, or because the surface attached polymer does not integrate as efficiently into the E. coli membrane (insertion into the membrane has been reported for several different antimicrobial peptides ${ }^{77}$ ).

For measurements of E. coli's cytoplasmic $\mathrm{pH}$ we use pHluorin and find that in vivo calibration curve is dependant on the agents used to collapse $\mathrm{pH}$. We do not understand the observations at present, but speculate that it could occur due to the interaction between the uncoupler (CCCP or indole) and the bacterium, e.g. CCCP can be actively exported by EmrAB-TolC pump ${ }^{78}$. Using pHluorin we show that the internal $\mathrm{pH}$ of the attached $E$. coli is kept between 7.3 and 8.4 and doesn't vary significantly with the surface coating. On all the tested surfaces in MM9 media the cytoplasmic pH decreases slightly in the course of the experiment, and the behaviour changes in LB medium, where cytoplasmic $\mathrm{pH}$ increases over the observation time. The result is not unexpected, as metabolic byproducts have been demonstrated to influence E. coli's cytoplasmic $\mathrm{pH}^{63,72,79-82}$. For example, glucose metabolism mainly produces organic acids as byproducts, such as acetate, lactate, formate, succinate etc. ${ }^{79}$. These organic acids are capable of crossing the inner membrane in their uncharged form dissociating in the cytoplasm, which causes full or partial collapse of the $\mathrm{pH}$ gradient across the membrane ${ }^{63,72,80}$. In the case of LB medium, the alkalinisation of the media due to E. coli's metabolism has been reported and attributed to the release of the amine-containing compounds ${ }^{81,82}$. In both cases, however, the change does not exceed $0.6 \mathrm{pH}$ units (an equivalent of $35.5 \mathrm{mV}$ of proton motive force).

We were able to quantify growth in all but one tested surface. On APTES surface we observed attachment and growth, but the attachment was not strong enough to support growth for sufficient amount of time needed to quantify it. Here we note that our flow rate of $4 \mu \mathrm{l} / \mathrm{min}$ was chosen to ensure a continuous supply of fresh oxygen and nutrients throughout our measurements. The average size of our flow chamber used for surface attachment is $17.5 \mu \mathrm{l}$, which means the media is exchanged in $\sim 5 \mathrm{~min}$. If we take into account $E$. coli's oxygen consumption 
rates $^{83,84}$ and the concentration of cells during imaging (calculated based on observed surface density), we obtain that in our flow chamber oxygen will be depleted in $14 \mathrm{~min}$ to $3.7 \mathrm{~h}$. Thus, flow rate could have been reduced (in particular for conditions in which oxygen consumption rate is lower) potentially allowing growth on APTES surfaces as well.

We performed our study using E. coli as the model organism, allowing us to place our results in the context of the relevant literature on E. coli's physiology and cell size and growth rate regulation ${ }^{8,48,50-57}$. We believe performing similar studies for other bacteria would be valuable for the community and we hope to see it in the future. We have also introduced a flatness score that can enable easier comparisons of attachment quality between such similar studies done on different bacteria.

In summary, we conclude that all the tested immobilisation protocols can be used for live cell imaging of $E$. coli without specifically affecting cells' main physiological traits. While we expect that our results will hold in most growth conditions it is worth noting that in some more extreme conditions (alkaline or acidic external pH, very high external osmolarity, etc) the effect on the physiology could be different and should be independently assessed by researchers.

\section{Materials and Methods}

Bacterial strains and growth conditions. The strain, EK03, is the Escherichia coli K-12 MG1655 strain with "sticky" flagella mutation ${ }^{17,85}$ and pkk223-3/pHluorin(M153R) plasmid. The plasmid containing pHluorin with M153R mutation to have better stability of fusion proteins ${ }^{70}$ was a kind gift from Dr. Tohru Minamino. SI Fig. 5 shows growth comparison of the two strains, EK03 and wild-type MG1655, in Lysogeny broth (LB: 1\% $\mathrm{w} / \mathrm{v}$ Bacto-Tryptone, $0.5 \% \mathrm{w} / \mathrm{v}$ yeast extract and $0.5 \% \mathrm{w} / \mathrm{v} \mathrm{NaCl}, \mathrm{pH} 6.8)$ and $\mathrm{MM} 9$ medium $\left(\mathrm{Na}_{2} \mathrm{HPO}_{4} 50 \mathrm{mM}\right.$, $\mathrm{NaH}_{2} \mathrm{PO}_{4} 20 \mathrm{mM}, \mathrm{NaCl} 8.5 \mathrm{mM}, \mathrm{NH}_{4} \mathrm{Cl} 20 \mathrm{mM}, \mathrm{CaCl}_{2} 0.1 \mathrm{mM}, \mathrm{KCl} 1 \mathrm{mM}, \mathrm{MgSO}_{4} 2 \mathrm{mM}, 0.5 \%$ glucose, and MEM Amino acides solution (Gibco, USA), $\mathrm{pH} 7.0$ ) at $37^{\circ} \mathrm{C}$ and $23^{\circ} \mathrm{C}$ shaken at $220 \mathrm{rpm}$. Cells were diluted from an overnight culture to achieve steady state growth ( 6 to 10 divisions before reaching OD $\sim 0.4$ ).

For imaging cells were inoculated in LB or MM9 medium from an overnight culture grown in LB. Cultures are grown for $2 \mathrm{~h}$ in $\mathrm{LB}$ and $4 \mathrm{~h}$ in MM9 meidum at $37^{\circ} \mathrm{C}$ with continuous shaking $(220 \mathrm{rpm})$ to reach optical density of $\sim .4$ (achieving $~ 3$ divisions). Before imaging cells were further diluted 1:60 into MM9 or LB for the surface immobilisation protocols. For comparison of our growth rates at different temperatures and in different media please see SI Table 2.

Microscope and microfluidic chambers. Bacterial growth assays were conducted using a motorised, inverted optical microscope (Ti-E, Nikon, Japan) with perfect focus system for time lapse observation. The microscope is equipped with a 100x Objective (Plan Apo $100 \times / 1.45$ NA lambda, Nikon, Japan), sCMOS Camera (Zyla 4.2, Andor, UK) and LED fluorescent excitation light source (PE4000, CoolLED, UK). Imaging was performed in phase-contrast and epifluorescence configuration, the latter was used for measuring the cytoplasmic $\mathrm{pH}$ with pHluorin. The exposure times for phase-contrast and epifluorescence imaging were 100 and $70 \mathrm{~ms}$ respectively, and images were recorded every $5 \mathrm{~min}$. The $\mathrm{pH}$ measurement using $\mathrm{pHluorin}$ was achieved by ratiometric method from two excitation wavelength of 395 and $470 \mathrm{~nm}$ and emission of $510 \mathrm{~nm}$ images. The excitation and emission was achieved by LED excitation light $(395 \mathrm{~nm}$ and $479 \mathrm{~nm})$ via a dual-band dichroic mirror $(403 / 502 \mathrm{~nm}$, FF403/502-Di01-25x36, Semrock, USA) and a dual-band bandpass emission filter (FF01-433/530-25, Semrock, USA).

To supply fresh oxygenated media throughout the experiment we use a flow chamber made as follows. Two $1.5 \mathrm{~mm}$ holes were drilled in a microscope slide $20 \mathrm{~mm}$ apart. PTFE tubing with inner diameter $0.96 \mathrm{~mm}$ was attached to the slide with epoxy glue, SI Fig. 10. The flow chamber was then created by attaching double sided tape or gene frame (Fisher Scientific, USA) to the slide and covering it with pre-coated or uncoated cover glass depending on the immobilisation protocol. Gene frame was used to create a larger chamber to fit the agarose pad, while sticky tape was used for all of the other protocols. Dimensions of the formed flow chamber are $3.5 \times 25 \times 0.2 \mathrm{~mm}$ for doubled sided tape, and $17 \times 28 \times 0.25 \mathrm{~mm}$ for gene frame. The flow chamber construction protocol varied slightly with different coating protocols. For the PLL "in chamber" and Cell-Tak coating methods, the flow chambers were sealed before coating. In other cases, the coverslips were coated prior to the flow chamber construction.

For all of the immobilisation assays medium was flown at $400 / \mathrm{min}$ flow rate at the end of the attachment protocol for $4 \mathrm{~min}$ to remove poorly attached cells, upon which the flow rate was altered to $4 / \mathrm{min}$ for the duration of the experiment $(12 \mathrm{~h}$ ). Media was flown with a syringe pump (Fusion 4000, Chemyx, USA). Before the imaging begun we identified a field of view with maximum number of "flat" cells ${ }^{18,24}$ for each of the surfaces, and the flatness score (see below for further details) is calculated on thus selected fields of view.

Immobilisation protocols. Preparation step: coverslip cleaning. The coverslip is sonicated in an ultrasonic bath (D150H, Delta, Taiwan) with saturated solution of $\mathrm{KOH}$ in ethanol for $30 \mathrm{~min}$. It is then rinsed with the deionised water and sonicated for further $30 \mathrm{~min}$ in deionised water. Cell do not attach to so treated glass without suitable coating. The cleaning step has been performed prior to all attachment protocols.

PLL "in-chamber". Surface of the flow chamber is coated with $0.1 \%$ poly-L-lysine (PLL) by flushing PLL through the channel for $\sim 10 \mathrm{~s}$ followed by washing it out with the excessive volume of growth medium (x20 times the volume of the chamber). Cells are then loaded into the flow chamber and incubated for 1 to 3 min to allow attachment, and then washed out as described under Microscopy and Microfluidic chambers section. The total length of time it took to prepare a flow chamber with cells attached is $\sim 40 \mathrm{~min}$, irrespective of the attachment method. 
PLL "rinsed". Coverslip is coated with the PLL prior to the flow chamber construction. 100 of the $0.01 \%$ PLL solution (diluted from P8920 Sigma-Aldrich, USA) is spread over approximate $1.5 \mathrm{~cm}^{2}$ area. The solution is allowed to sit on the coverslip for $30 \mathrm{~min}$, then washed off with $5 \mathrm{ml}$ of deionised water. The coated coverslip is then used to construct a flow chamber. The cells are attached as above.

PLL "air-dried". The protocol is similar to the "rinsed" method. Here, the PLL solution on the coverslip is air dried fully, typically for $1.5 \mathrm{~h}$ at room temperature. The coated coverslip is then washed with $5 \mathrm{ml}$ deionised water and used to construct a flow chamber. The cells are attached as above.

PEI. 200 of $1 \%$ PEI is spread out on the coverslip covering the area the size of the flow chamber tunnel. Solution is incubated on the surface for $10 \mathrm{~s}$, and washed off thoroughly with $100 \mathrm{ml}$ of deionised water. The volume of the water should be much higher than that of the PEI to leave no residual PEI molecules that are not attached to the glass surface. Otherwise (e.g. if we use $5 \mathrm{ml}$ of water), we observe cells blebbing ${ }^{86,87}$ and dying when grown on the surface. We also notice that the "in-chamber" coating method is not applicable for PEI in MM9 media, as it leads to MM9 precipitation in the chamber caused by the leftover free PEI molecules. This is not the case for LB; "in-chamber" coating method can be used with PEI and LB ${ }^{18}$. The cells are subsequently attached as described above.

Cell-Tak. Cell-Tak working mixture is prepared by adding 14 of Cell-Tak $(1.16 \mathrm{mg} / \mathrm{mL})$ to $174 \mathrm{NaHCO}_{2}(\mathrm{pH}$ 8.0) followed by immediate vortexing. A pre-assembled flow chamber is incubated with Cell-Tak mixture for $20 \mathrm{~min}$, then washed with $3 \mathrm{ml}$ of deionised water. $3 \mathrm{ml}$ of MM9 is flushed through the chamber before attaching the cells. Finally, cells are attached as above.

APTES. A coverslip was incubated in 2\% APTES for $2 \mathrm{~h}$, and then rinsed with $5 \mathrm{ml}$ deionised water and $5 \mathrm{ml}$ acetone. The remaining acetone was air-dried with nitrogen. The coated coverslip was later used for the flow chamber construction. Cells are attached as above.

Agarose gel pad. For the agarose gel pad, the flow chamber area was $17 \times 28 \mathrm{~mm}^{2}$. The gel pad was created by adding a 5 droplet of melted $1 \%$ agarose to the middle of the flow chamber. 0.5 of the cell culture was added onto the solidified pad and covered immediately with the coverslip. The fresh medium was constantly circulated around the agarose "island" during the experiment.

Image analysis. Cell segmentation. Phase contrast images of the cells were analysed with custom written Python script and Image ${ }^{88}$. In phase-contrast microscopy, cells appear as dark objects on a light background, with a characteristic white halo, Fig. 1 inset. Cells are segmented with Watershed algorithm ${ }^{89,90}$ implemented as ImageJ Marker-controlled Watershed plugin ${ }^{91}$. The algorithm treats an image as a topological surface where the pixel intensity corresponds to the area height. It then identifies the edge of the cell as the watershed separating neighboring drainage basins. The limit of watershed algorithm grows based on the background intensity. After the segmentation, the cell length is calculated by PSICIC algorithm (Projected System of Internal Coordinates from Interpolated Contours) ${ }^{92}$. Briefly, the algorithm finds two poles of a cell as points that are the greatest Euclidean distance apart, thus creating two curves. On each of the two contour curves the algorithm evenly distributes equal number of points and then connects them (effectively creating width lines). Finally, the center line, i.e. the length of the cell, runs along the middle of the width lines ${ }^{92}$. We define the cell width as the average of all the width lines which are greater than nine-tenths of the maximum width line. The division time is determined manually by analyzing the cells from the onset of constriction. It is difficult to set the criteria for an exact division time point based on the morphology or the gray scale intensity, because the cells can tilt (in the $\mathrm{x}$ and y plane) during the division. The manual criteria are, for example, the detachment of one of the daughter cells (we often find that the daughter cell detaches due to flow), or centre lines of the two cells might no longer overlap. Subjectivity in setting a division time point can cause time error of about $\pm 10 \mathrm{~min}$, which affects division time measurements but not the estimates of the growth rate $b$.

Flatness score. To quantify the quality of attachment on a given surface we define a flatness score. We start by extending the center line running along the middle of the cell to include cell background and split it into 12 points to obtain a histogram of intensity along the extended centre line. The height of each histogram bin is the average grey scale value of pixels whose positions are located within the interval of the bin. Next, the 12-bin histogram is normalised to 1. Lastly, values of the bins on each side of the cell that are equidistant from the middle are subtracted and summed to obtain the flatness score. A perfectly flat cell should have a symmetric profile and a flatness score of zero.

Numerical and statistical method. Growth curve fitting. The growth of the cell follows $L(t)=L_{b} \times e^{b t}$, where $L_{b}$ is the cell initial length, $t$ time in minutes, $b$ the growth rate ${ }^{50}$. The equation with two fitting parameters, $L_{b}$ and $b$, is fitted to the cell length using Levenberg-Marquardt algorithm ${ }^{93}$, a non-linear least squares method, implemented using Scipy, a numerical package in Python ${ }^{94}$. Initial parameters are identified by first fitting a polynomial to the logarithmic growth of the cell length.

Box plot. The borders of the box and the middle line in our box plots indicate the three quartiles of the data. The range of whiskers is 1.5 of the interquartile range, and data outside the whiskers are the outliers (displayed as dots). All of the data points are superimposed on the box plot as transparent points in the form of swarm plot. 
Data deposition. Raw data generated as part of this work are available at datashare.is.ed.ac.uk/ handle/10283/2058.

Received: 27 July 2019; Accepted: 5 November 2019;

Published online: 19 December 2019

\section{References}

1. Dobell, C. Antony van Leeuwenhoek and his "Little animals" (Harcourt, Brace and company, 1932).

2. Elowitz, M. B., Levine, A. J., Siggia, E. D. \& Swain, P. S. Stochastic Gene Expression in a Single Cell. Sci. (80-.). 297, 1183-1186 (2002).

3. Taheri-Araghi, S., Brown, S. D., Sauls, J. T., McIntosh, D. B. \& Jun, S. Single-Cell Physiology. Annu. Rev. Biophys. 44, 123-142, https:// doi.org/10.1146/annurev-biophys-060414-034236. arXiv:1011.1669v3 (2015).

4. Raskin, D. M. \& de Boer, P. A. J. Rapid pole-to-pole oscillation of a protein required for directing division to the middle of Escherichia coli. Proc. Natl. Acad. Sci. 96, 4971-4976, https://doi.org/10.1073/pnas.96.9.4971 (1999).

5. Ghodke, H., Ho, H. \& van Oijen, A. M. Single-molecule live-cell imaging of bacterial DNA repair and damage tolerance. Biochem. Soc. Trans. 46, 23-35, https://doi.org/10.1042/BST20170055 (2018).

6. Hol, F. J. H. \& Dekker, C. Zooming in to see the bigger picture: Microfluidic and nanofabrication tools to study bacteria. Sci. (80-.). 346 (2014).

7. Leygeber, M. et al. Analyzing microbial population heterogeneity - expanding the toolbox of microfluidic singlecell cultivations. J. Mol. Biol., http://www.sciencedirect.com/science/article/pii/S0022283619302323, https://doi.org/10.1016/j.jmb.2019.04.025 (2019).

8. Wang, P. et al. Robust Growth of Escherichia coli. Curr. Biol. 20, 1099-1103 (2010).

9. Humphries, J. et al. Species-Independent Attraction to Biofilms through Electrical Signaling. Cell 168, 200-209.e12, https://doi. org/10.1016/j.cell.2016.12.014 (2017).

10. Okumus, B. et al. Single-cell microscopy of suspension cultures using a microfluidics-assisted cell screening platform. Nat. Protoc. 13, 170-194, https://doi.org/10.1038/nprot.2017.127 (2018).

11. Hadizadeh Yazdi, N., Guet, C. C., Johnson, R. C. \& Marko, J. F. Variation of the folding and dynamics of the Escherichia coli chromosome with growth conditions. Mol. Microbiol. 86, 1318-1333, https://doi.org/10.1111/mmi.12071 (2012).

12. Moffitt, J. R., Lee, J. B. \& Cluzel, P. The single-cell chemostat: An agarose-based, microfluidic device for high-throughput, single-cell studies of bacteria and bacterial communities. Lab Chip 12, 1487-1494, http://www.ncbi.nlm.nih.gov/pubmed/22395180, http:// www.pubmedcentral.nih.gov/articlerender.fcgi?artid=PMC3646658, https://doi.org/10.1039/c2lc00009a (2012).

13. Priest, D. G., Tanaka, N., Tanaka, Y. \& Taniguchi, Y. Micro-patterned agarose gel devices for single-cell high-throughput microscopy of E. coli cells. Sci. Rep. 7, 17750, https://doi.org/10.1038/s41598-017-17544-2 (2017).

14. Yang, D., Jennings, A. D., Borrego, E., Retterer, S. T. \& Ma“nnik, J. Analysis of factors limiting bacterial growth in pdms mother machine devices. Front. Microbiol. 9, 871, https://doi.org/10.3389/fmicb.2018.00871 (2018).

15. Lo, C.-J., Sowa, Y., Pilizota, T. \& Berry, R. M. Mechanism and kinetics of a sodium-driven bacterial flagellar motor. Proc. Natl. Acad. Sci. USA 110, E2544-E2551, https://doi.org/10.1073/pnas.1301664110 (2013).

16. Rosko, J., Martinez, V., Poon, W. \& Pilizota, T. Osmotaxis in Escherichia coli through changes in motor speed. Proc. Natl. Acad. Sci. USA 114, E7969-E7976, https://doi.org/10.1073/pnas.1620945114. 1703.03926. (2017).

17. Krasnopeeva, E. Single cell measurements of bacterial physiology traits during exposure to an external stress. Ph.D. thesis, The University of Edinburgh (2018).

18. Pilizota, T. \& Shaevitz, J. W. Fast, multiphase volume adaptation to hyperosmotic shock by Escherichia coli. PLoS One 7, e35205, https://doi.org/10.1371/journal.pone.0035205 (2012).

19. Meyer, R. L. et al. Immobilisation of living bacteria for AFM imaging under physiological conditions. Ultramicroscopy, https://doi. org/10.1016/j.ultramic.2010.06.010(2010).

20. Uphoff, S. \& Kapanidis, A. N. Studying the organization of DNA repair by single-cell and single-molecule imaging. DNA Repair (Amst). 20, 32-40, https://doi.org/10.1016/j.dnarep.2014.02.015 (2014).

21. Sydor, A. M., Czymmek, K. J., Puchner, E. M. \& Mennella, V. Super-Resolution Microscopy: From Single Molecules to Supramolecular Assemblies. Trends Cell Biol. 25, 730-748, https://doi.org/10.1016/j.tcb.2015.10.004 (2015).

22. Coltharp, C. \& Xiao, J. Superresolution microscopy for microbiology. Cell. Microbiol. 14, 1808-1818 (2012).

23. Pilizota, T. \& Shaevitz, J. Plasmolysis and cell shape depend on solute outer-membrane permeability during hyperosmotic shock in e. coli. Biophys. J. 104, 2733-2742, https://doi.org/10.1016/j.bpj.2013.05.011 (2013).

24. Buda, R. et al. Dynamics of Escherichia coli's passive response to a sudden decrease in external osmolarity. Proc. Natl. Acad. Sci. 113, E5838-E5846, https://doi.org/10.1073/pnas.1522185113, https://www.pnas.org/content/113/40/E5838.full.pdf (2016).

25. Tipping, M. J., Steel, B. C., Delalez, N. J., Berry, R. M. \& Armitage, J. P. Quantification of flagellar motor stator dynamics through in vivo proton-motive force control. Mol. Microbiol. 87, 338-347, https://groups.physics.ox.ac.uk/molecularmotors/pdfsofpapers/ MolMicroTippingpRPMFstators.pdf, https://doi.org/10.1111/mmi.12098. (2013).

26. Kapanidis, A. N., Uphoff, S. \& Stracy, M. Understanding protein mobility in bacteria by tracking single molecules. J. Mol. Biol. 430, 4443-4455, http://www.sciencedirect.com/science/article/pii/S0022283618303905, https://doi.org/10.1016/j.jmb.2018.05.002 Plasticity of Multi-Protein Complexes (2018).

27. Parry, B. R. et al. The bacterial cytoplasm has glass-like properties and is fluidized by metabolic activity. Cell 156, 183-194, https:// doi.org/10.1016/j.cell.2013.11.028. NIHMS150003 (2014).

28. Liu, B., Hasrat, Z., Poolman, B. \& Boersma, A. J. Decreased Effective Macromolecular Crowding in Escherichia coli Adapted to Hyperosmotic Stress. J. Bacteriol. 201, e00708-18 (2019).

29. Munder, M. C. et al. A pH-driven transition of the cytoplasm from a fluid- to a solid-like state promotes entry into dormancy. Elife 5, https://doi.org/10.7554/eLife.09347 (2016).

30. Cowan, S. E., Liepmann, D. \& Keasling, J. D. Development of engineered biofilms on poly- 1-lysine patterned surfaces. Biotechnol. Lett. 23, 1235-1241, https://doi.org/10.1023/A:1010581503842 (2001).

31. Touhami, A., Jericho, M. H., Boyd, J. M. \& Beveridge, T. J. Nanoscale characterization and determination of adhesion forces of Pseudomonas aeruginosa pili by using atomic force microscopy. J. Bacteriol. 188, 370-377, http://www.ncbi.nlm.nih.gov/ pubmed/16385026, http://www.pubmedcentral.nih.gov/articlerender.fcgi?artid=PMC1347306, https://doi.org/10.1128/ JB.188.2.370-377.2006 (2006).

32. Katsu, T., Tsuchiya, T. \& Fujita, Y. Dissipation of membrane potential of Escherichia coli cells induced by macromolecular polylysine. Biochem. Biophys. Res. Commun. 122, 401-6 (1984).

33. Colville, K., Tompkins, N., Rutenberg, A. D. \& Jericho, M. H. Effects of poly(L-lysine) substrates on attached Escherichia coli bacteria. Langmuir 26, 2639-2644, https://doi.org/10.1021/la902826n (2010).

34. Conte, M., Aliberti, F., Fucci, L. \& Piscopo, M. Antimicrobial activity of various cationic molecules on foodborne pathogens. World J. Microbiol. Biotechnol. 23, 1679-1683, https://doi.org/10.1007/s11274-007-9415-6 (2007).

35. Bakshi, S., Siryaporn, A., Goulian, M. \& Weisshaar, J. C. Superresolution imaging of ribosomes and RNA polymerase in live Escherichia coli cells. Mol. Microbiol. 85, 21-38 (2012). 
36. Mohapatra, S., Choi, H., Ge, X., Sanyal, S. \& Weisshaar, J. C. Spatial Distribution and Ribosome-Binding Dynamics of EF-P in Live Escherichia coli. MBio 8, e00300-17 (2017).

37. Lonergan, N., Britt, L. \& Sullivan, C. Immobilizing live Escherichia coli for AFM studies of surface dynamics. Ultramicroscopy 137, 30-39, https://doi.org/10.1016/j.ultramic.2013.10.017 (2014).

38. Suo, Z., Avci, R., Yang, X. \& Pascual, D. W. Efficient immobilization and patterning of live bacterial cells. Langmuir 24, 4161-4167, https://doi.org/10.1021/la7038653 (2008).

39. Wang, S., Arellano-Santoyo, H., Combs, P. A. \& Shaevitz, J. W. Measuring the bending stiffness of bacterial cells using an optical trap. J. Vis. Exp. 8-9, https://doi.org/10.3791/2012 (2010).

40. Dickson, J. S. \& Koohmaraie, M. Cell surface charge characteristics and their relationship to bacterial attachment to meat surfaces. Appl. Environ. Microbiol. 55, 832-836, http://aem.asm.org/ (1989).

41. Sowa, Y. et al. Direct observation of steps in rotation of the bacterial flagellar motor. Nat. 437, 916-919, https://doi.org/10.1038/ nature04003 (2005).

42. Pilizota, T. et al. A molecular brake, not a clutch, stops the rhodobacter sphaeroides flagellar motor. Proc. Natl. Acad. Sci. 106, 11582-11587, https://doi.org/10.1073/pnas.0813164106, https://www.pnas.org/content/106/28/11582.full.pdf (2009).

43. Sowa, Y. \& Berry, R. M. Bacterial flagellar motor. Q. Rev. Biophys. 41, 103-132, https://groups.physics.ox.ac.uk/molecularmotors/ pdfsofpapers/QRBSowaBFMreview2008.pdf, https://doi.org/10.1017/S0033583508004691 (2008).

44. Waite, J. H. \& Tanzer, M. L. Polyphenolic substance of Mytilus edulis: Novel adhesive containing L-dopa and hydroxyproline. Sci. (80-.). 212, 1038-1040, https://doi.org/10.1126/science.212.4498.1038 (1981).

45. Papov, V. V., Diamond, T. V., Biemann, K. \&Waite, J. H. Hydroxyarginine-containing polyphenolic proteins in the adhesive plaques of the marine mussel Mytilus edulis. J. Biol. Chem. 270, 20183-20192, https://doi.org/10.1074/jbc.270.34.20183. arXiv:1011.1669v3 (1995).

46. Lee, B. P., Messersmith, P., Israelachvili, J. \& Waite, J. Mussel-inspired adhesives and coatings. Annu. Rev. Mater. Res. 41, 99-132, https://doi.org/10.1146/annurev-matsci-062910-100429 (2011).

47. Gokaltun, A., Yarmush, M. L., Asatekin, A. \& Usta, O. B. Recent advances in nonbiofouling PDMS surface modification strategies applicable to microfluidic technology. Technology 05, 1-12, http://www.ncbi.nlm.nih.gov/pubmed/28695160, http://www. pubmedcentral.nih.gov/articlerender.fcgi?artid=PMC5501164, https://doi.org/10.1142/s2339547817300013 (2017).

48. Schaechter, M., MaalØe, O. \& Kjeldgaard, N. O. Dependency on medium and temperature of cell size and chemical composition during balanced growth of salmonella typhimurium. Microbiol. 19, 592-606, https://doi.org/10.1099/00221287-19-3-592 (1958).

49. Herendeen, S. L., VanBogelen, R. A. \& Neidhardt, F. C. Levels of major proteins of Escherichia coli during growth at different temperatures. J. Bacteriol. 139, 185-194, https://jb.asm.org/content/139/1/185.full.pdf (1979).

50. Cermak, N. et al. High-throughput measurement of single-cell growth rates using serial microfluidic mass sensor arrays. Nat. Biotechnol. 34, 1052-1059, http://www.ncbi.nlm.nih.gov/pubmed/27598230, http://www.pubmedcentral.nih.gov/articlerender. fcgi?artid=PMC5064867, https://doi.org/10.1038/nbt.3666 (2016).

51. Koppes, L. J., Meyer, M., Oonk, H. B., de Jong, M. A. \& Nanninga, N. Correlation between size and age at different events in the cell division cycle of Escherichia coli. J. Bacteriol. 143, 1241-1252, https://jb.asm.org/content/143/3/1241.full.pdf (1980).

52. Lin, J. \& Amir, A. Population growth with correlated generation times at the single-cell level. arXiv e-prints arXiv:1806.02818 1806.02818 (2018).

53. Lin, J. \& Amir, A. The effects of stochasticity at the single-cell level and cell size control on the population growth. Cell Syst. 5, 358-367.e4, https://doi.org/10.1016/j.cels.2017.08.015 (2017).

54. Si, F. et al. Invariance of initiation mass and predictability of cell size in Escherichia coli. Curr. Biol. 27, 1278-1287, http://www. sciencedirect.com/science/article/pii/S0960982217302919, https://doi.org/10.1016/j.cub.2017.03.022 (2017).

55. Mannik, J. et al. Robustness and accuracy of cell division in Escherichia coli in diverse cell shapes. Proc. Natl. Acad. Sci. 109, 6957-6962, https://doi.org/10.1073/pnas.1120854109 (2012).

56. Osella, M., Nugent, E. \& Cosentino Lagomarsino, M. Concerted control of Escherichia coli cell division. Proc. Natl. Acad. Sci. USA 111, 3431-5, https://doi.org/10.1073/pnas.1313715111 (2014).

57. Scott, M., Gunderson, C. W., Mateescu, E. M., Zhang, Z. \& Hwa, T. Interdependence of cell growth and gene expression: Origins and consequences. Sci. 330, 1099-1102, https://doi.org/10.1126/science.1192588. (2010).

58. Gorden, J. \& Small, P. L. Acid resistance in enteric bacteria. Infect. Immun. 61, 364-7 (1993).

59. Lin, J., Lee, I. S., Frey, J., Slonczewski, J. L. \& Foster, J. W. Comparative analysis of extreme acid survival in Salmonella typhimurium, Shigella flexneri, and Escherichia coli. J. Bacteriol. 177, 4097-4104, https://doi.org/10.1128/jb.177.14.4097-4104.1995 (1995).

60. Slonczewski, J. L., Fujisawa, M., Dopson, M. \& Krulwich, T. A. Cytoplasmic pH Measurement and Homeostasis in Bacteria and Archaea. Adv. Microb. Physiol. 55, https://doi.org/10.1016/S0065-2911(09)05501-5 (2009).

61. Zilberstein, D., Agmon, V., Schuldiner, S. \& Padan, E. Escherichia coli intracellular pH, membrane potential, and cell growth. J. Bacteriol. 158, 246-252 (1984).

62. Slonczewski, J. L., Rosen, B. P., Alger, J. R. \& Macnab, R. M. pH homeostasis in Escherichia coli: measurement by 31P nuclear magnetic resonance of methylphosphonate and phosphate. Proc. Natl. Acad. Sci. USA 78, 6271-6275, https://doi.org/10.1073/ pnas.78.10.6271 (1981).

63. Lund, P., Tramonti, A. \& De Biase, D. Coping with low pH: Molecular strategies in neutralophilic bacteria. FEMS Microbiol. Rev. 38, 1091-1125, https://doi.org/10.1111/1574-6976.12076 (2014).

64. Mitchell, P. Coupling of phosphorylation to electron and hydrogen transfer by a chemi-osmotic type of mechanism. Nat. 191, 144-148, https://doi.org/10.1038/191144a0 (1961).

65. Bearne, S. L. Illustrating the effect of $\mathrm{pH}$ on enzyme activity using Gibbs energy profiles. J. Chem. Educ. 91, 84-90, https://doi. org/10.1021/ed400229g (2014).

66. Martinez, K. A. et al. Cytoplasmic pH response to acid stress in individual cells of Escherichia coli and Bacillus subtilis observed by fluorescence ratio imaging microscopy. Appl. Environ. Microbiol. 78, 3706-3714, https://doi.org/10.1128/AEM.00354-12 (2012).

67. Chakraborty, S., Winardhi, R. S., Morgan, L. K., Yan, J. \& Kenney, L. J. Non-canonical activation of OmpR drives acid and osmotic stress responses in single bacterial cells. Nat. Commun. 8, 1587, https://doi.org/10.1038/s41467-017-02030-0 (2017).

68. Miller, S. I., Kukral, A. M. \& Mekalanos, J. J. A two-component regulatory system (phoP phoQ) controls Salmonella typhimurium virulence. Proc. Natl. Acad. Sci. USA 86, 5054-5058, https://doi.org/10.1073/pnas.86.13.5054 (1989).

69. Choi, J. \& Groisman, E. A. Acidic pH sensing in the bacterial cytoplasm is required for Salmonella virulence. Mol. Microbiol. 101, 1024-1038, https://doi.org/10.1111/mmi.13439 (2016).

70. Morimoto, Y. V., Kojima, S., Namba, K. \& Minamino, T. M153R mutation in a pH-sensitive green fluorescent protein stabilizes its fusion proteins. PLoS One 6, e19598, https://doi.org/10.1371/journal.pone.0019598 (2011).

71. Krasnopeeva, E., Lo, C.-J. \& Pilizota, T. Single-cell bacterial electrophysiology reveals mechanisms of stressinduced damage. Biophys. J. 0, https://linkinghub.elsevier.com/retrieve/pii/S0006349519303923, http://arxiv.org/abs/1809.05306, https://doi.org/10.1016/j. bpj.2019.04.039. 1809.05306 (2019).

72. Wilks, J. C. et al. Acid and base stress and transcriptomic responses in bacillus subtilis. Appl. Environ. Microbiol. 75, 981-990, https:// doi.org/10.1128/AEM.01652-08, https://aem.asm.org/content/75/4/981.full.pdf (2009).

73. Zarkan, A. et al. Indole Pulse Signalling Regulates the Cytoplasmic pH of E. coli in a Memory-Like Manner. Sci. Rep. 9, 3868, https:// doi.org/10.1038/s41598-019-40560-3 (2019).

74. Wallden, M., Fange, D., Lundius, E. G., Özden, B. \& Elf, J. The synchronization of replication and division cycles in individual e. coli cells. Cell 166, 729-739, https://doi.org/10.1016/j.cell.2016.06.052 (2016). 
75. Thomas, P., Terradot, G., Danos, V. \& Weiße, A. Y. Sources, propagation and consequences of stochasticity in cellular growth. Nat. Commun. 9, 4528, https://doi.org/10.1038/s41467-018-06912-9 (2018).

76. Cattoni, D. I., Fiche, J. B., Valeri, A., Mignot, T. \& No"llmann, M. Super-Resolution Imaging of Bacteria in a Microfluidics Device. PLoS One 8, https://doi.org/10.1371/journal.pone.0076268 (2013).

77. Brogden, K. A. Antimicrobial peptides: Pore formers or metabolic inhibitors in bacteria? Nat. Rev. Microbiol. 3, 238-250, https://doi. org/10.1038/nrmicro1098 (2005).

78. Griffith, J. M. et al. Experimental evolution of Escherichia coli k-12 in the presence of proton motive force (pmf) uncoupler carbonyl cyanide m-chlorophenylhydrazone selects for mutations affecting pmf-driven drug efflux pumps. Appl. Environ. Microbiol. 85, https://doi.org/10.1128/AEM.02792-18, https://aem.asm.org/content/85/5/e02792-18.full.pdf (2019).

79. Bennett, B. D. et al. Absolute metabolite concentrations and implied enzyme active site occupancy in Escherichia coli. Nat. Chem. Biol. 5, 593-599, https://doi.org/10.1038/nchembio.186.Absolute (2009).

80. Kitko, R. D. et al. Cytoplasmic acidification and the benzoate transcriptome in bacillus subtilis. Plos One 4, 1-12, https://doi. org/10.1371/journal.pone.0008255 (2009).

81. Lazar, S. W., Almiro'n, M., Tormo, A. \& Kolter, R. Role of the Escherichia coli SurA protein in stationary-phase survival. J. Bacteriol. 180, 5704-5711 DOI D - NLM: PMC107631 EDAT- 1998/10/29 MHDA- 1998/10/29 00:01 CRDT-1998/10/29 00:00 PST - ppublish (1998).

82. Molina, P. M., Parma, A. E. \& Sanz, M. E. Survival in acidic and alcoholic medium of Shiga toxin-producing Escherichia coli O157:H7 and non-O157:H7 isolated in Argentina. BMC Microbiol. 3, 1-6, https://doi.org/10.1186/1471-2180-3-17 (2003).

83. Garcia-Ochoa, F., Gomez, E., Santos, V. E. \& Merchuk, J. C. Oxygen uptake rate in microbial processes: An overview. Biochem. Eng. J. 49, 289-307, https://people.bath.ac.uk/nk376/Oxygen\{_\}Uptake\{_\}Garcia-Ochoa\{_\}etal.pdf, https://doi.org/10.1016/j. bej.2010.01.011 (2010).

84. Martinez-Salas, E., Martin, J. A. \& Vicente, M. Relationship of Escherichia coli density to growth rate and cell age. J. Bacteriol. 147, 97-100, http://www.ncbi.nlm.nih.gov/pubmed/7016845, http://www.pubmedcentral.nih.gov/articlerender.fcgi?artid=PMC216012 (1981).

85. Kuwajima, G. Construction of a minimum-size functional flagellin of Escherichia coli. J. Bacteriol. 170, 3305-3309, https://doi. org/10.1128/jb.170.7.3305-3309.1988 (1988).

86. Yao, Z., Kahne, D. \& Kishony, R. Distinct Single-Cell Morphological Dynamics under Beta-Lactam Antibiotics. Mol. Cell 48, 705-712, https://doi.org/10.1016/j.molcel.2012.09.016 (2012).

87. Fletcher, E., Pilizota, T., Davies, P. R., McVey, A. \& French, C. E. Characterization of the effects of n-butanol on the cell envelope of E. coli. Appl. Microbiol. Biotechnol. 100, 9653-9659, https://doi.org/10.1007/s00253-016-7771-6 (2016).

88. Schindelin, J. et al. Fiji: an open-source platform for biological-image analysis. Nat. methods 9, 676 (2012).

89. Meyer, F. \& Beucher, S. Morphological segmentation. J. Vis. Commun. Image Represent. 1, 21-46, https://doi.org/10.1016/10473203(90)90014-m (1990).

90. Soille, P. Morphological image analysis: principles and applications (Springer Science \& Business Media, 1999).

91. Legland, D., Arganda-Carreras, I. \& Andrey, P. MorphoLibJ: integrated library and plugins for mathematical morphology with ImageJ. Bioinforma. btw413, https://doi.org/10.1093/bioinformatics/btw413 (2016).

92. Guberman, J. M., Fay, A., Dworkin, J., Wingreen, N. S. \& Gitai, Z. PSICIC: Noise and asymmetry in bacterial division revealed by computational image analysis at sub-pixel resolution. PLoS Comput. Biol. 4, https://doi.org/10.1371/journal.pcbi.1000233 (2008).

93. Moré, J. The levenberg-marquardt algorithm: Implementation and theory. In Watson, G. (ed.) Numerical Analysis, vol. 630 of Lecture Notes in Mathematics, 105-116, https://doi.org/10.1007/BFb0067700. (Springer Berlin Heidelberg, 1978).

94. Jones, E., et al. SciPy: Open source scientific tools for Python, http://www.scipy.org/ (2001).

\section{Acknowledgements}

This project is supported by the Human Frontier Science Program Grant (RGP0041/2015) to T.P., C.J.L. and F.B. C.J.L. is financially supported by the Ministry of Science and Technology, Republic of China under contract No. MOST-107-2112-M-008-025-MY3. EK was supported by the Global Research and Principal's Career Development PhD Scholarships. We thank Tom Shimizu and Victor Caldas (AMOLF) for sharing the APTES protocol of immobilization.

\section{Author contributions}

Y.K.W., E.K., F.B., T.P. and C.J.L. designed research. Y.K.W., S.Y.L. and E.K. performed research and analysed data. Y.K.W., S.Y.L., E.K., F.B., T.P. and C.J.L. interpreted results and wrote the paper. All authors reviewed the manuscript.

\section{Competing interests}

The authors declare no competing interests.

\section{Additional information}

Supplementary information is available for this paper at https://doi.org/10.1038/s41598-019-55798-0.

Correspondence and requests for materials should be addressed to T.P. or C.-J.L.

Reprints and permissions information is available at www.nature.com/reprints.

Publisher's note Springer Nature remains neutral with regard to jurisdictional claims in published maps and institutional affiliations.

Open Access This article is licensed under a Creative Commons Attribution 4.0 International License, which permits use, sharing, adaptation, distribution and reproduction in any medium or format, as long as you give appropriate credit to the original author(s) and the source, provide a link to the Creative Commons license, and indicate if changes were made. The images or other third party material in this article are included in the article's Creative Commons license, unless indicated otherwise in a credit line to the material. If material is not included in the article's Creative Commons license and your intended use is not permitted by statutory regulation or exceeds the permitted use, you will need to obtain permission directly from the copyright holder. To view a copy of this license, visit http://creativecommons.org/licenses/by/4.0/.

(C) The Author(s) 2019 